\title{
Perencanaan Strategis Madrasah Pembangunan UIN Jakarta Tahun 2011-2014
}

\author{
Dian Nuraini $^{1)}$, Suryadi $^{2)}$, Siti Zulaikha ${ }^{3)}$ \\ ${ }^{1,2,3}$ Pasca Sarjana Manajemen Pendidikan, Universitas Negeri Jakarta, Indonesia \\ Email ${ }^{1}$ :nuraini.dian@gmail.com \\ Email $^{2}$ : suryadi@unj.ac.id \\ Email $^{3}$ : Siti-Zulaikha@unj.ac.id
}

\begin{abstract}
Abstrak: Perencanaan strategis dalam dunia pendidikan berfungsi sebagai alat untuk mengarahkan kegiatan pendidikan agar efektif dan efisien. Penelitian ini bertujuan untuk mendapatkan gambaran utuh mengenai penyusunan dan pelaksanaan perencanaan strategis tahun 2011-2014 di Madrasah Pembangunan. Bagaimana tahapan-tahapan penyusunan dan pelaksanaan dari awal sosialisasi sampai dengan evaluasi termasuk didalamnya proses penerjemahan dokumen perencanaan strategis menjadi dokumen panduan teknis pelaksanaan program dan kegiatan. Metode penelitian ini adalah qualitatif deskriptif dengan peneliti sebagai instrumen penelitian atau disebut juga sebagai human instrument. Penentuan nara sumber dilakukan berdasarkan rekomendasi dari nara sumber inti secara purposive sampling dan snowball. Teknik pengumpulan data melakukan observasi langsung, memotret tempat penelitian, merekam wawancara dengan nara sumber dan mengumpulkan data-data atau dokumen yang didapatkan dari nara sumber. Temuan dari penelitian (1) Perencanaan strategis Madrasah Pembangunan tahun 2011-2014 telah disusun sesuai dengan standar merujuk pada Permendiknas Nomor: 2 Tahun 2010. (2) Perencanaan strategis Madrasah Pembangunan tahun 2011-2014 telah dilaksanakan dengan baik dan telah menjadi acuan dalam setiap kebijakan yang diputuskan oleh manajemen.
\end{abstract}

Kata kunci : Proses Perencanaan, Perencanaan Strategis, Madrasah

\begin{abstract}
Strategic planning in education has a function as a roadmap to direct educational activities run effectively and efficiently. The purposes of this study are to analyze and to obtain a complete picture of the preparation and implementation of strategic planning for 2011-2014 in Madrasah Pembangunan. What kind of stages of preparation and implementation has to be made from the start of socialization to evaluation, including the tranformation process of strategic planning documents into technical guidance documents for program and activity implementation. This research method is descriptive qualitative with the researcher as a research instrument or also known as a human instrument. Determination of interviewees are based on recommendations from the key informant by purposive sampling and snowball. The technique of collecting data is direct observations, collecting photograph from the research site, recording interviews with informants and collecting data or documents obtained from resource persons. Findings from the research are: (1) The strategic planning for Madrasah Pembangunan for 2011-2014 has been appropriately prepared in accordance with the standards referring to Permendiknas Number 2 of 2010. (2) The strategic planning for the Madrasah Development for 2011-2014 has been implemented well and has become a reference in every program's policies decided by management.
\end{abstract}

Keywords: Planning Process, Strategic Planning, Islamic Education

\section{PENDAHULUAN}

Pada data Emis Pendis (Education Management Information System Pendidikan Islam) yang diakses pada September 2020, jumlah madrasah negeri masih sangat sedikit dibandingkan dengan madrasah swasta, jumlah madrasah negeri adalah sebanyak $4.010(4,9 \%)$ sedangkan madrasah swasta 
Volume 72, Nomor 2, Desember 2020

sebanyak $78.408 \quad(95,1 \%)$. Sebagaimana

\section{\& Chart Lembaga}

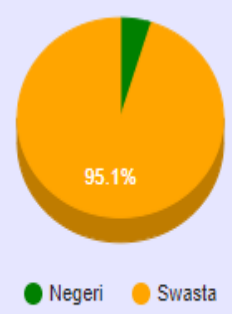

Gambar 1. 1. Grafik Presentasi Madrasah Negeri dan Swasta di Indonesia (sumber: Emis Pendis, 2020)

Berdasarkan data dari Direktorat Jenderal Pendidikan Islam capaian yang diperoleh pada ujian nasional (UN) tahun 2019 rata-rata nilai UN Madrasah Tsanawiyah (MTs) negeri 49,92 dan swasta 46,98, lebih rendah dari yang dicapai oleh skor sekolah umum (SMP) yaitu 53,00 dan 52,27. Terjadi kesenjangan antara MTs negeri dan swasta yang mencapai 2,94 poin. Hal yang sama dapat ditemukan di Madrasah Aliyah (MA) dengan kesenjangan skor sebesar 3,48 poin. Kualifikasi guru madrasah yang terdaftar di Direktorat Jenderal Pendidikan Islam sudah berijazah $\mathrm{S} 1$ dan bersertifikat namun berdasarkan hasil ujian kompetensi guru (UKG) tahun 2015, skor yang diperoleh oleh guru madrasah rata-rata adalah 49,6 dari 100 masih dibawah skor rata-rata UKG nasional yaitu 53,5.

Dalam hal mutu sarana dan prasarana madrasah, ruang kelas termasuk kondisi fasilitas pendidikan yang lain seperti laboratorium dan perpustakaan beserta perlengkapannya belum memenuhi standar layak minimal yang ditetapkan pada Standar Nasional Pendidikan (SNP). Berdasarkan data tahun 2018, persentase yang dipenuhi oleh setiap jenjang di madrasah adalah sebagai berikut: Raudhatul Athfal (RA): 66,64\%, Madrasah Ibtidaiyah (MI): 59,18\%, Madrasah Tsanawiyah (MTs): 64,69\%, dan Madrasah Aliyah/Madrasah Aliyah Kejuruan (MA/MAK): 72,30 \%. Angka tersebut masih jauh untuk dapat memenuhi standar minimal SNP. digambarkan pada diagram berikut:

\section{Lill Chart Lembaga Sesuai Jenjang}

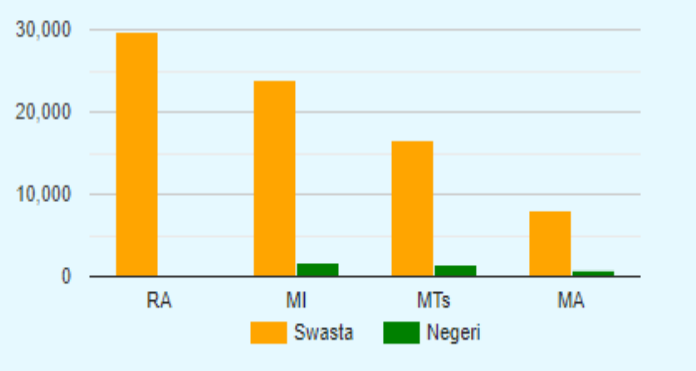

Dewasa ini, perkembangan program/kegiatan bagi pendidikan Agama Islam sudah semakin membaik dan terencana. Aturan-aturan mengenai pendidikan agama Islam diatur khusus dalam perundang-undangan dan berada dibawah naungan Kementerian Agama RI Direktorat Jendral Pendidikan Islam. Meskipun demikian masih banyak yang perlu dibenahi untuk menjadikan kualitas rata-rata madrasah setara dengan sekolah umum.

Sekolah maupun madrasah sebagai lembaga pendidikan dimana dalam pengelolaan jangka pendek maupun jangka panjang sangat memerlukan perencanaan yang matang agar pengelolaan sekolah menjadi efektif dan efisien. Dengan adanya perencanaan yang baik dapat memberikan gambaran langkah-langkah yang diperlukan, alternatif-alternatif pemecahan masalah, hal-hal yang diutamakan serta anggaran yang diperlukan.

Perencanaan adalah tahapan awal manajemen sebagai landasan bagi semua pelaksanaan organisasi lainnya. Perencanaan merupakan bagian penting dalam pelaksanaan manajemen di setiap lembaga baik lembaga bisnis maupun sosial. Untuk memulai setiap kegiatan, diperlukan adanya perencanaan sebagai arahan dan panduan agar kegiatan dapat berjalan sesuai tujuannya dan dapat dipertanggungjawabkan. Di dalam merencanakan kegiatan yang berjangka waktu cukup lama dibutuhkan perencanaan yang dapat mengukur berbagai tantangan dan hambatan dan memberikan arahan pelaksanaan sesuai 
kemampuan dan kapasitas yang dimiliki lembaga. Masyarakat yang dinamis dan kebijakan pemerintah yang berubah-ubah menuntut para pemegang keputusan agar cepat tanggap mengambil tidakan untuk menghadapi tantangan tersebut. Perencanaan strategis menjadi hal yang penting untuk memperjelas arah masa depan dengan memberikan dasar yang masuk akal untuk setiap pengambilan keputusan, menetapkan prioritas, dan meningkatkan kinerja organisasi. Salah satu fungsi penting dari perencanaan strategis bagi lembaga pendidikan diantaranya adalah untuk efisiensi dana dan efektivitas kinerja. Menurut Hinton (2012):

strategic planning was conducted in the realm of corporate or military operations, where mission driven long-term objectives and short-term actions needed to be efficiently integrated through a type of administrative coordination most colleges and universities never aspired to emulate.

Perencanaan strategis telah dilakukan dalam ranah operasi perusahaan atau militer, dengan tujuan jangka panjang yang digerakkan oleh misi dan tindakan jangka pendek yang perlu diintegrasikan secara efisien melalui koordinasi secara administratif dimana sebagian besar perguruan tinggi dan universitas tidak pernah ingin meniru.

Praktisi di pendidikan tidak memandang ide tentang pengembangan produk, pertumbuhan industri, peluang pasar, manajemen resiko dan melayani pelanggan merupakan bagian dari budaya di dunia pendidikan. Akan tetapi seiring dengan perkembangan dan pertumbuhannya, kesulitankesulitan dan hambatan-hambatan menjadi semakin banyak serta beragam membuat para praktisi di pendidikan menyingkirkan batasan tersebut.

Menurut Steiner G. A. (1997):

strategic planning is a process. It is a process that begins with the setting of organizational aims, define strategies and policies to achieve them, and develops detailed plans to make sure that the strategies are implemented so as to achieve the ends sought. It is a process of deciding in advance what kind of planning effort is to be undertaken, when it is to be done, how it is to be done, who is going to do it, what will be done with the results.
Perencanaan strategis adalah proses. Proses yang diawali dengan menentukan tujuan organisasi, mendefinisikan strategi-strategi dan kebijakan-kebijakan untuk meraihnya dan mengembangkan rencana-rencana untuk memastikan strategi-strateginya telah diterapkan untuk mencapai hasil akhir. Proses memutuskan diawal perencanaan usaha apa yang harus dilaksanakan, kapan harus selesainya, bagaimana menyelesaikannya, siapa yang akan melaksanakannya, apa yang akan dilakukan dengan hasilnya.

Perencanaan strategis di lembaga pendidikan lebih banyak berfungsi sebagai alat untuk mengatur pelaksanaan pendidikan lebih efektif dan efisien. Perencanaan strategis di sekolah Menurut Bell (2004) adalah:

Strategic planning in school management now encapsulates a range of activities that are now required of staff in schools and, through school improvement planning, has come to be the only legitimate approach for schools in preparing for their future. For improvement in school, therefore, is now perceived as both central to the implementation of the Goverment's educational policy and to success of its wider economic and social agendas by providing a workforce with appropriate skills and producing good citizens.

perencanaan strategis manajemen sekolah sekarang ini merangkum berbagai kegiatan yang diharapkan dari staf sekolah dan melalui perencanaan peningkatan sekolah menjadi satusatunya pendekatan yang sah bagi sekolah untuk mempersiapkan masa depannya. Oleh karena itu untuk peningkatan sekolah, perencanaan yang baik seharusnya dapat memprediksi segala kemungkinan yang dapat terjadi di masa yang akan datang dan membuat perencanaan langkah-langkah untuk menghadapi segala kemungkinan baik peluang maupun tantangan di masa depan. Diperlukan banyak informasi dan analisa yang memperhatikan semua aspek internal dan eksternal untuk membuat keputusan dalam perencanaan strategis.

Sebagian besar sekolah umum menggunakan perencanaan sebagai roadmap dalam pengelolaannya terutama sekolahsekolah umum swasta unggulan, sebaliknya dengan madrasah swasta sangat sedikit yang 
sudah menggunakan perencanaan strategis, sebagian besar masih sangat sederhana dalam pengelolaanya dan minim perencanaan. Madrasah Pembangunan UIN Jakarta merupakan salah satu madrasah yang menggunakan peencanaan strategis dalam pengelolaannya dan termasuk madrasah unggulan yang berprestasi.

Perencanaan strategis bukanlah sebagai tujuan akhir dalam perencanaan strategis itu sendiri, karena perencanaan strategis hanyalah merupakan kumpulan konsep untuk membantu para pemimpin membuat keputusan penting dan melakukan tindakan penting bagi keberlangsungan dan kejayaan organisasi. Diperlukan kerjasama tim dan komitmen yang kuat dari para pemangku kebijakan dan pelaksana agar perencanaan strategis dapat disusun dan dilaksanakan dengan optimal. Menurut Bryson (2011), tahapan-tahapan penting yang harus dilaksanakan dalam penyusunan perencanaan strategis agar perencanaan strategis dapat disusun dengan baik adalah:

1. Mengidentifikasi faktor internal dan eksternal sebagai analisis SWOT

2. Menetapkan isu-isu strategis yang dihadapi

3. Merumuskan strategi untuk menghadapi isu-isu maupun perubahan kebijakan

4. Menetapkan visi organisasi yang efektif

5. Mengembangkan proses implementasi agar dapat dilaksanakan secara efektif dan menggabungkan perencanaan strategis ke dalam sistem organisasi.

Terdapat hal-hal yang perlu diperhatikan pada penyusunan perencanaan strategis yang seringkali terjadi di setiap lembaga dan menjadi penyebab ketidakberhasilan perencanaan strategis. Diantaranya adalah kebanyakan tim penyusun perencanaan strategis memiliki tugas utama lain sehingga tidak dapat secara penuh berkonsentrasi memikirkan dan mendedikasikan dirinya untuk penyusunan perencanaan strategis.

Dalam proses perencanaan strategis terdapat beberapa tahapan pendekatan yang perlu dilakukan untuk bisa mengidentifikasi dan menanggapi tantangan-tantangan yang dihadapi manajemen.. Perlu dicatat bahwa tidak ada aturan baku tentang kerangka yang benar atau pola tertentu yang harus diikuti. Namun banyak kerangka tahapan dalam perencanaan strategis yang satu dengan lainnya memiliki kesamaan pada proses utamanya.
Menurut Maleka (2014);

many frameworks cycle through some variation on some very basic phases:

- Analysis or assessment, where an understanding of the current internal and external environments is developed;

- Strategy formulation, where high level strategy is developed and a basic organisation level strategic plan is documented;

- Strategy execution, where the high level plan is translated into more operational planning and action items, and

- Evaluation or sustainment / management phase, where ongoing refinement and evaluation of performance, culture, communications, data reporting, and other strategic management issues occurs.

beberapa fase yang sangat dasar pada proses perencanaan adalah sebagai berikut:

- Analisis atau penilaian, di mana pemahaman tentang lingkungan internal dan eksternal saat ini dikembangkan;

- Perumusan strategi, di mana strategi tingkat tinggi dikembangkan dan rencana strategis tingkat organisasi dasar didokumentasikan;

- Eksekusi strategi, di mana rencana tingkat tinggi diterjemahkan ke dalam perencanaan operasional dan item tindakan, dan

- Tahap evaluasi atau keberlanjutan/manajemen, di mana terjadi penyempurnaan dan evaluasi kinerja, budaya, komunikasi, pelaporan data, dan masalah manajemen strategis lainnya.

Poin penilaian akhir dari rencana strategis suatu institusi muncul ketika rencana sebelumnya berakhir dan rencana baru sedang dikembangkan. Fokus penilaian tidaklah pada pencapaian item tertentu dalam suatu perencanaan, tetapi lebih pada melihat bagaimana proses perencanaan dapat ditingkatkan. Gambar 1.2 menunjukkan proses siklus pengembangan, pelaksanaan dan peninjauan pada proses perencanaan dan kapan seharusnya proses tersebut harus mencakup cerminan bagaimana hal tersebut dapat berhasil dan perubahan apa yang mungkin dapat membuatnya lebih baik. 


\section{Process to Develop, Implement, and Review a Planning Process}

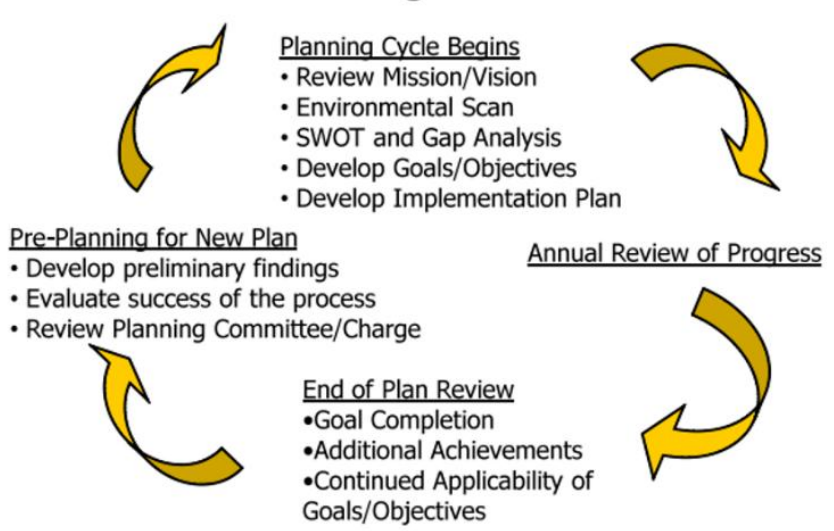

Gambar 1. 2 Proses Pengembangan, Penerapan dan Peninjauan Proses Perencanaan (sumber: Hinton, 2012)

Implementasi yang efisien dari proses perencanaan strategis didasari oleh sistem terintegrasi yang berfungsinya dengan baik dan partisipasi penuh yang efektif dari semua pemangku kepentingan terkait. Menurut Schlebusch \& Mokhatle (2016) berikut ini adalah aspek-aspek penting untuk diingat ketika melaksanakan perencanaan:

1. Menterjemahkan setiap insiatif dalam perencanaan strategis dengan mengukuhkan lima poin kritis yaitu: siapa, apa, kenapa, kapan dan sumberdaya yang dibutuhkan; ketika menyusun perencanaan strategis pembagian tugas harus ditetapkan kepada masing-masing orang atau kelompok tertentu siapa yang akan menyusun alasan untuk setiap rencana usaha, menetapkan tenggat waktu, dan menentukan kapan dibutuhkan pendanaan.

2. Menyambungkan perencanaan strategis dengan proses anggaran sekolah; agar dapat memperkirakan sumberdaya dan dana yang dibutuhkan untuk melaksanakan perencanaan strategis.

3. Tujuan dari perencanaan strategis harus didahulukan dan jadwal yang realistis harus ditetapkan; biasanya perencanaan strategis berkisar antara 3-5 tahun, diperlukan penjadwalan yang jelas dan rinci untuk mengawal pelaksanaannya.

4. Perencanaan strategis harus disampaikan kepada seluruh pihak-pihak yang terkait; seluruh pihak terkait harus berperan aktif dan antusias melaksanakan perannya masing-masing.

\section{METODOLOGI PENELITIAN}

Penelitian ini dilaksanakan selama hampir empat bulan yaitu sejak tanggal 23 Maret sampai dengan 22 Juli 2020, di Madrasah Pembangunan UIN JAKARTA Kompleks UIN Syarif Hidayatullah, Jl. Ibnu Taimia IV Tangerang Selatan, Banten 15419 Indonesia. Penelitian ini dilakukan dengan menggunakan metode kualitatif deskriptif. Metode deskriptif adalah suatu metode penelitian dengan menggambarkan secara mendalam dan sistematis suatu objek, baik berupa kondisi, sistem pemikiran, ataupun suatu peristiwa pada masa sekarang dengan menggunakan berbagai media baik audio maupun visual untuk dapat mendeskripsikan berdasarkan fakta dan akurat objek yang diteliti, sehingga dapt terlihat jelas fakta-fakta, sifat-sifat serta hubungan antar fenomena yang diselidiki. 
Menurut Sukmadinata N. S (2011), penelitian kualitatif adalah suatu penelitian yang bertujuan yang ditujukan untuk mendeskripsikan dan menganalisis fenomena, peristiwa, aktivitas sosial, sikap, kepercayaan, persepsi, pemikiran orang secara individual maupun kelompok.

Instrumen penelitian dalam penelitian ini adalah peneliti sendiri atau disebut juga sebagai human instrument. Penentuan nara sumber dalam penelitian ini secara purposive sampling, dan bersifat snow ball dimana setelah mendapatkan informasi yang cukup dari sumber data, peneliti akan menentukan sumber data berikutnya berdasarkan dari sumber data sebelumnya. Teknik Pengumpulan Data dengan melakukan pengamatan secara langsung, mendokumentasikan tempat penelitian, menyimpan bukti wawancara dengan nara sumber dan menggali serta mengumpulkan data-data atau dokumen dari nara sumber. Teknik Analisis Data sudah dilakukan sejak awal berupa pengamatan menyeluruh atau grand tour sampai dengan selesai penelitian dengan cara membuat catatan dari temuantemuan, membuat kronologis, menyusun data, mempelajari data, memverifikasi data dan menterjemahkan data sehingga dapat menghasilkan teori.

Menurut Sukmadinata (2011), langkahlangkah pengumpulan dan analisis data adalah: (1) Perencanaan, yaitu dengan merumuskan dan membuat batasan-batasan masalahan kemudian merumuskan pertanyaan-pertanyaan penelitian yang akan diarahkan pada kegiatan pengumpulan data. (2) Memulai pengumpulan data, melalui interview dilengkapi dengan data pengamatan dan data dokumen (triangulasi) (3) Pengumpulan data dasar (4) Pengumpulan data penutup (5) Melengkapi untuk memeriksa kelengkapan data yang dibbutuhkan. Pengujian keabsahan data dilakukan untuk menguji keabsahan data, yaitu dengan melakukan uji: kredibilitas, transferabilitas, dependabelitas dan konfirmabilitas.

\section{PEMBAHASAN}

Dasar hukum yang digunakan dalam penyusunan perencanaan strategis Madrasah pembangunan 2011-2014 adalah merujuk kepada:
1. Undang-undang Republik Indonesia Nomor 20 Tahun 2003 tentang Sistem Pendidikan Nasional

2. Undang-undang Republik Indonesia Nomor 14 Tahun 2005 tentang Guru dan Dosen

3. UU Nomor 23 Tahun 2002 Tentang Perlindungan Anak

4. PP Nomor 74 Tahun 2008 Tentang Guru

5. PP Nomor 19 Tahun 2005 Tentang Standar Nasional Pendidikan

6. PP Nomor 17 Tahun 2010 Tentang Pengelolaan dan Penyelenggaraan Pendidikan

7. PP Nomor 55 Tahun 2008, Tentang Pendidikan Agama dan Keagamaan

8. PP Nomor 17 Tahun 2007 Tentang RPJP, RPJM

9. Instruksi Presiden Nomor 7 tahun 1999 tentang Akuntabilitas Kinerja Instansi Pemerintah

10. Permendiknas Nomor 2 Tahun 2011 Tentang Ujian Sekolah/Madrasah dan UN pada sekolah Dasar/Madrasah Ibtidaiyah dan Sekolah Dasar Luar Biasa Tahun Pelajaran 2010/2011

11. Permendiknas Tentang Berbagai Standar Nasional Pendidikan (Contoh Permendiknas Nomor : 22, 23, 24 dst tahun 2006)

12. Permenag Nomor : 2 Tahun 2008, tentang SKL, Standar Isi Pendidikan agama dan Bahasa arab di madrasah

13. Permenag. Tahun 2011 tentang UAMBN

14. Permendiknas Nomor 2 Tahun 2010 Tentang RENSTRA

15. Inmendiknas Nomor: $1 / \mathrm{U} / 2002$ tentang Pelaksanaan Akuntabilitas di lingkungan Kemendiknas

16. Keputusan Rektor IAIN Syarif Hidayatullah Jakarta Nomor 06 Tahun 1988 tentang Pelimpahan Tugas, Wewenang dan Tanggung jawab Penyelenggara Madrasah Pembangunan UIN Jakarta

17. Keputusan Ketua Yayasan Syarif Hidayatullah Jakarta Nomor 04 Tahun 2007 tentang Organisasi dan Tata Kerja Madrasah Pembangunan UIN Jakarta

18. Keputusan Direktur Madrasah Pembangunan UIN Syarif Hidayatullah Jakarta Nomor: 22 Tahun 2009 Tentang Pengangkatan Tim Penyusun Rencana Induk Pengembangan dan Rencana 
Strategis Madrasah Pembangunan UIN Jakarta.

Tahapan-tahapan yang dilakukan dalam penyusunan Perencanaan Strategis Madrasah Pembangunan 2011-2014 adalah sebagai berikut:

- Menyamakan persepsi, brainstorming dan memberikan komitmen penuh terhadap proses penyusunan dan pelaksanaan perencanaan diantara para pemangku kepentingan.

- Membentuk tim dan melakukan pembagian tugas sesuai kapasitas masingmasing. Tim yang dibentuk terdiri dari perwakilan tiap unit yang ada.

- Mengidentifikasi kebijakan-kebijakan, peraturan-peraturan, hukum-hukum, yang berkaitan dengan Madrasah Pembangunan. Hal ini dilakukan sebagai dasar penetapan mandat.

- Memperjelas visi, misi dan tujuan dari Madrasah Pembangunan.

- Membuat analisis SWOT

- Merumuskan strategi-strategi berdasarkan analisis SWOT

- Menyusun dokumen perencanaan strategis dan melakukan uji publik dengan mengadakan rapat pleno guna mengumpulkan saran dan masukan terkait perencanaan strategis yang sedang disusun.

- Melakukan pengesahan sekaligus sosialisasi ke tiap unit terkait.

Tim penyusun perencanaan strategis Madrasah Pembangunan terdiri dari para praktisi dan pakar terutama dalam bidang perencanaan, sehingga tidak memerlukan konsultan dari lembaga lain. Pihak luar yang dilibatkan adalah komite, pihak Fakultas Ilmu Tarbiyah dan Kependidikan (FITK) UIN Jakarta dan pemuka agama di lingkungan Madrasah Pembangunan. Tahapan-tahapan yang dilakukan Madrasah Pembangunan dalam penyusunan perencanaan strategisnya sudah sesuai dengan standar umum yang dikemukakan oleh para ahli. Dimana langkahlangkah yang dilakukan telah mengarah kepada tindakan, hasil dan evaluasi. Tahapan yang belum ada dan perlu ditambahkan dalam proses penyusunan adalah tahapan tindak lanjut dari sosialisasi agar dapat menjembatani proses penyusunan dengan tahapan pelaksanaan.
Tahapan-tahapan dasar yang berulang dan sering ditemui disetiap proses perencanaan strategis adalah menganalisa faktor lingkungan baik internal maupun eksternal, kemudian berdasarkan analisa tersebut dirumuskan strategi-strategi organisasi, selanjutnya adalah melaksanakan strategi tersebut dan terakhir adalah mengevaluasi keseluruhan tahapan yang dilalui untuk ditindaklanjuti sebagai perbaikan dan bahan analisa perencanaan strategis mendatang.

Menurut Maleka (2014), ada beberapa alasan mengapa perencanaan strategis tidak terbentuk dengan benar atau tidak terlaksana dengan baik, diantaranya adalah:

- Manajemen senior tidak mengikuti proses yang ditentukan untuk menyelesaikan tugas ini.

- Proses tersebut didelegasikan ke kelompok perencanaan, atau ditugaskan ke berbagai fungsional

- Manajemen senior tidak menyisihkan waktu untuk menyusun rencana strategis sebagai suatu produk kerja tim kolektif.

- Organisasi tidak memahami untuk apa rencana strategis sebenarnya dirancang menyediakan. Oleh karena itu, Renstra merupakan rencana bisnis taktis dengan tahun jamak ekstrapolasi. Hanya sedikit yang membahas arah strategis yang sebenarnya.

- Manajemen senior harus mengikuti proses atau metodologi yang ditetapkan yang akan menghasilkan sebuah rencana strategis tepat waktu dan efisien namun komprehensif.

- Rencana dikembangkan tetapi tidak ada proses untuk mengkomunikasikannya di seluruh organisasi dan membangun keselarasan organisasi untuk implementasinya.

- Rencana dikembangkan tanpa pedoman implementasi sama sekali. Paling banter, itu diterapkan berkeping-keping. Paling buruk, itu tidak didanai dan diabaikan.

Keberhasilan pelaksanaan dari strategistrategi yang telah disusun akan bergantung kepada petunjuk pelaksanaannya. Petunjuk secara umum dikemukakan oleh Bryson (2011) sebagai berikut:

1. Secara sadar dan berhati-hati merencanakan dan mengatur pelaksanaan secara strategis. 
2. Mengembangkan dokumen-dokumen pelaksanaan strategi termasuk indikator kunci dan rencana pelaksanaan beserta pihak-pihak yang bertanggungjawab.

3. Mencoba perubahan yang dapat diperkenalkan secara mudah dan cepat.

4. Gunakan pendekatan manajemen program dan proyek kapanpun dimungkinkan.

5. Himpun cukup orang, waktu, perhatian, dana, administrasi dan dukungan layanan serta sumberdaya lainnya untuk meyakinkan suksesnya pelaksanaan.

6. Sambungkan inisiatif strategi baru dengan pelaksanaan yang sedang berjalan.

7. Kerjakan dengan cepat untuk menghindari persaingan yang tidak perlu dan tidak diinginkan dengan prioritasprioritas yang baru.

8. Fokus pada menjaga dan mengembangkan koalisi dari para pelaksana, penasehat dan kelompokkelompok yang berkepentingan dengan maksud agar efektif implementasi dari perubahan-perubahan dan bersedia untuk menjaganya selama pelaksanaan.

9. Pastikan aturan dan pelaksanaan dari legislatif, eksekutif, dan administrasi memfasilitasi bukannya menghalangi pelaksanaan.
10. Fikirkan dengan hati-hati tentang bagaimana perselisihan akan diselesaikan dan didasari norma yang berlaku.

11. Ingatlah bahwa perubaha besar, dan bahkan yang kecil sekalipun, diikuti dengan perubahan pada budaya organisasi.

12. Tekankan pembelajaran.

13. Fikirkan dengan hati-hati bagaimana teknologi informasi dan komunikasi dapat membantu mendukung pelaksanaan dan usaha pembelajaran yang berlangsung.

14. Ciptakan sistem yang dapat dipertanggungjawabkan sehingga meyakinkan pemegang kebijakan utama bahwa aturan-aturan, hukum dan kebutuhan pertanggungjawaban kinerja dasar telah terpenuhi.

15. Bertahanlah! Seiring waktu akan dapat berhasil selama dilakukan dengan sungguh sungguh.

Tahapan pelaksanaan perencanaan strategis yang dilaksanakan di Madrasah Pembangunan merupakan tahapan berulang membentuk siklus selama masa berlakunya perencanaan strategis tersebut. Beban dan tanggung jawab dibagi berdasarkan hirarki dalam struktur organisasi berikut: 


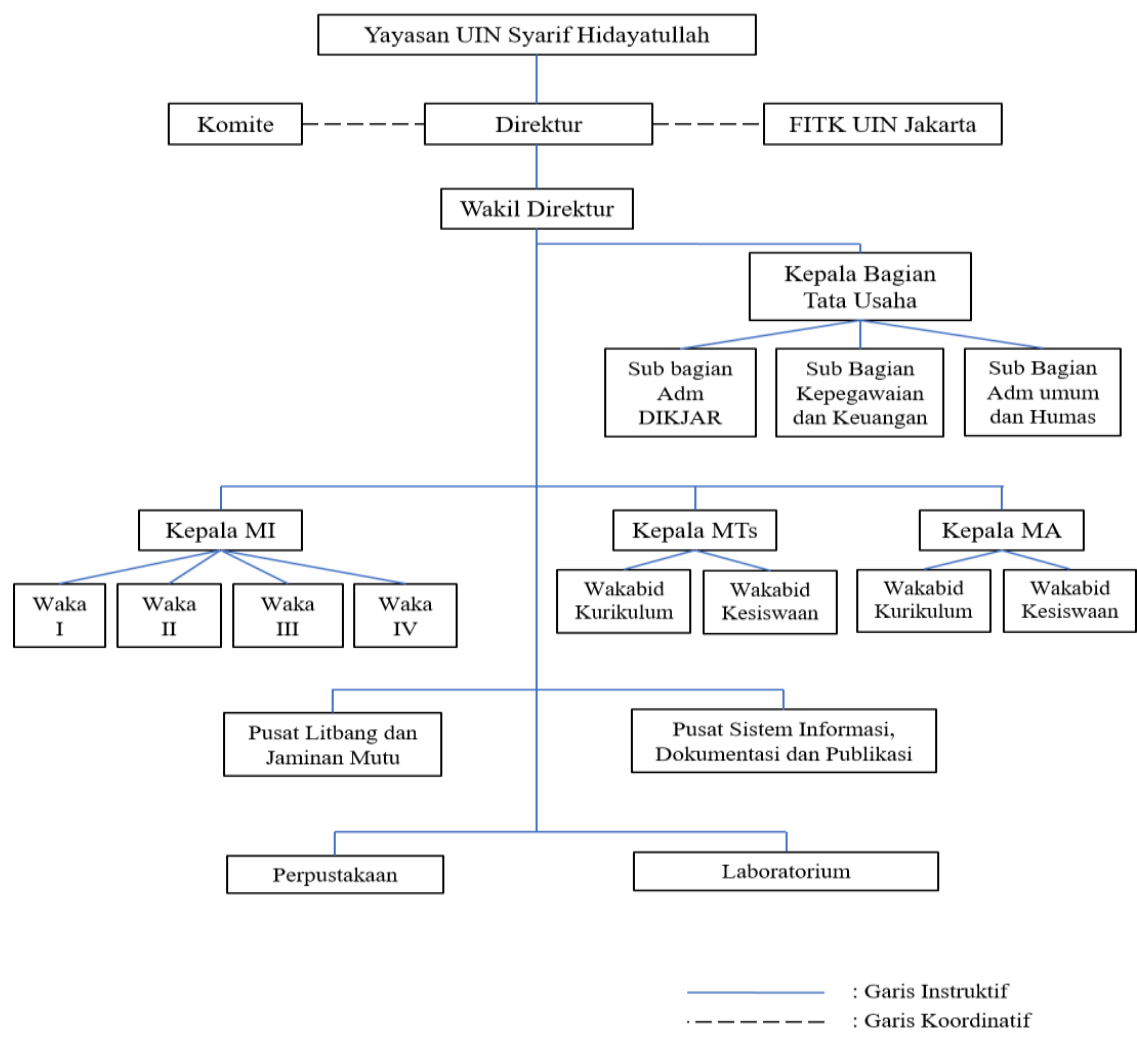

Gambar 1. 2. Struktur Organisasi Madrasah Pembangunan Pada Perencanaan Strategis tahun 2011-2014 (sumber: Rencana Strategis Madrasah Pembangunan tahun 2011-2014)

Tahapan pelaksanaan perencanaan strategisnya adalah sebagai berikut:

- Perumusan perencanaan strategis ke dalam kebijakan-kebijakan sebagai standar dan acuan pelaksanaan kegiatan. Kebijakankebijakan ini dilaksanakan di level direktur.

- Perumusan kebijakan direktur sebagai standar dan acuan untuk menetapkan target unit-unit dalam penyusunan programprogram kegiatan. Target-target unit ini kemudian akan dipresentasikan oleh setiap kepala unit untuk mendapatkan persetujuan dari direktur.

- Pelaksanaan program-program kegiatan dibawah tanggung jawab kepala unit masing-masing.
- Rapat koordinasi dan pengarahan harian dilakukan secara rutin di setiap unit untuk pendelegasian tugas dan pembekalan pelaksanaan program kegiatan muncul dan untuk terus mengawal pelaksanaan program kegiatan sehingga dapat segera ditindaklanjuti jika ada permasalahan.

- Evaluasi, audit ISO 9001 dan audit internal dilaksanakan setiap tahun satu kali sebagai kontrol dan penilaian pencapaian dari targettarget yang telah direncanakan. Selain itu juga untuk memantau sesuai timeline-nya.

- Penyusunan laporan berdasarkan hasil audit ISO dan internal sebagai bahan masukan untuk penyusunan perencanaan berikutnya. 


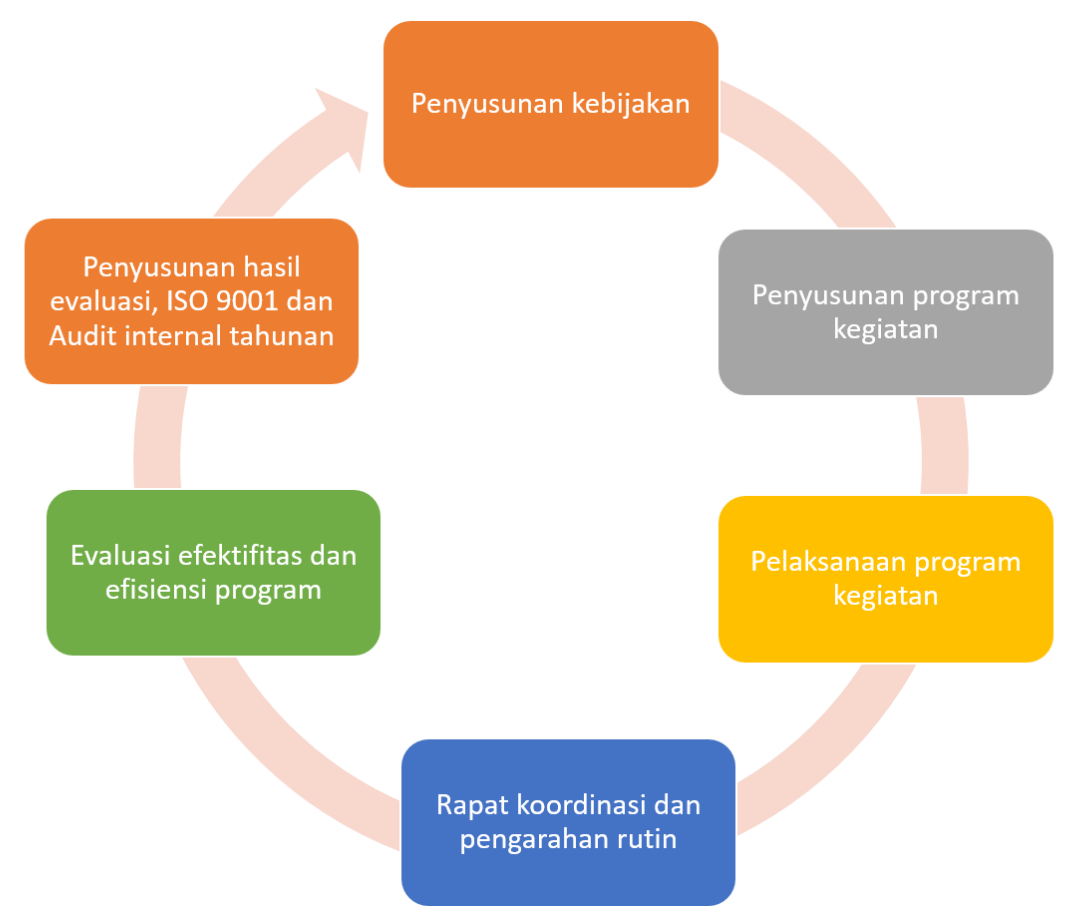

Gambar 1. 3 Siklus Tahapan Pelaksanaan Rencana Strategis Madrasah Pembangunan Tahun 2011 2014

Menurut Wyk dan Moeng (2014) bahwa: "The efficient implementation of a strategic planning process is based on having in place a well-functioning and integrated system and on obtaining effective participation by all relevant stakeholders. A wide range of policies form part of the current system". Proses pelaksanaan perencanaan strategis yang efisien tergantung pada peranan sistem yang berfungsi baik dan terintegrasi, dan dalam mendapatkan partisipasi efektif dari seluruh pemegang kepentingan yang terkait. Kolaborasi dukungan dan peranan efektif dari pemegang kebijakan dan sistem terbaik yang terintegrasi dapat membuat pelaksanaan rencana strategis menjadi efisien.

Pada tahap pelaksanaan, yang tidak kalah penting dan harus dilakukan adalah proses evaluasi. Proses penilaian atau evaluasi yang dilaksanakan setiap tahun di Madrasah Pembangunan adalah Evaluasi Diri Madrasah (EDM) yang dilakukan di masing-masing satuan unit untuk mengukur capaian di tiap bagian Madrasah Pembangunan UIN Jakarta sesuai delapan Standar Pendidikan Nasional dan dilakukan audit internal yaitu Audit Jaminan Mutu (AJM) yang dilaksanakan oleh tim Pusat Penelitian dan Pengembangan Jaminan Mutu (P3JM) Madrasah Pembangunan.
Evaluasi Diri Madrasah (EDM) dilaksanakan setiap tahun dalam rangka mengukur posisi Madrasah Pembangunan UIN Jakarta pada tingkat standar pendidikan nasional mengacu pada Peraturan Pemerintah Nomor 19 tahun 2005 tentang Standar Nasional Pendidikan, dengan target tercapai pada tahap tertinggi di semua tingkat satuan pendidikan di setiap delapan Standar Nasional Pendidikan. Evaluasi terhadap penyelenggaraan pendidikan Madrasah Pembangunan UIN Jakarta dilakukan terhadap delapan Standar Pendidikan yang meliputi:

1. Standar Isi;

2. Standar Proses;

3. Standar Kompetensi Lulusan;

4. Standar Pendidik dan Tenaga Kependidikan;

5. Standar Sarana dan Prasarana;

6. Standar Pengelolaan;

7. Standar Pembiayaan, dan

8. Standar Penilaian.

Proses pelaksanaan perencanaan strategis tahun 2011-2014 di Madrasah Pembangunan telah berjalan dengan baik dan telah diaplikasikan dalam setiap kebijakan-kebijakan dan juga menjadi target pencapaian di setiap program kegiatan yang dilaksanakan. 


\section{KESIMPULAN}

Tahapan-tahapan yang dilakukan dalam penyusunan perencanaan strategis Madrasah Pembangunan sudah mencakup standar umum dalam tahapan penyusunan perencanaan strategis menurut Bryson (2011). langkahlangkah yang dilakukan telah mengarah kepada

\section{DAFTAR PUSTAKA}

Allison, M., \& Kaye, J. (2015). Strategic Planning for Nonprofit Organizations. New Jersey: John WIlley \& Son, Inc.

Bell, L. (2004). Strategic Planning in Primary Schools: a tale of no sigfinicance? Management in Education, 33-36.

Bryson, J. M. (2011). Strategic Planning for Public and Nonprofit Organizations. San Fransisco: John Wiley \& Sons, Inc.

Bryson, J. M., Crosby, B. C., \& Bryson, J. K. (2009). Understanding Strategic Planning and the Formulation and Implementation of Strategic Plans as a Way of Knowing: The Contributions of Actor-Network Theory. International Public Management Journal, 172-207.

Dr. Burhan, N. (1994). Manajemen Strategik. Jakarta: PT. Pustaka Binaman Pressindo.

Fatah, N. (2013). Landasan Manajemen Pendidikan. Bandung: PT. Remaja Rosdakarya.

Hinton, E. K. (2012). A Pracatical Guide to Strategic Planning in Higher Education. Brookdale: Society for College and University Planning.

Hu, J., Liu, H., Chen, Y., \& Qin, J. (2017). Strategic Planning and The Stratification of Chinese Higher Education Institutions. International Journal of Educational Development.

maleka, s. (2014). STRATEGY MANAGEMENT AND tindakan, hasil dan evaluasi. Tahapan yang belum ada dan perlu ditambahkan dalam proses penyusunan adalah tahapan tindak lanjut. Pelaksanaan perencanaan strategis tahun 20112014 telah dilakukan dengan baik dan telah terintegrasi dengan sistem kegiatan di Madrasah Pembangunan.

\section{STRATEGIC PLANNING} PROCESS. DTPS Strategic Planning \& MonitoringAt: PretoriaVolume: volume 1 (hal. 30). South Africa: Research Gate. Montana, P., \& Charnov, B. (2008). Management. New York, Hauppauge. Diambil kembali dari https://en.wikipedia.org/wiki/Plan ning\#cite_note-7

Nolan, T. M., Goodstein, L. D., \& Goostein, J. (2008). Applied Strategic Planning. An Introduction. San Fransisco: Pfeiffer A WIlley Imprint.

Olsen, E. (2012). Strategic Planning Kit for Dummies. New Jersey: John WIlley \& Son, Inc.

Olsen, J. B. (1982). The Game Plan: Governance with Foresight. Washington, DC: Council of State Planning Agencies.

Salusu, J. (1996). Pengambilan Keputusan Strategik Untuk Organisasi Publik dan Organisasi Nonprofit. Jakarta: PT. Grasindo.

Schlebusch, G., \& Mokhatle, M. (2016). Strategic Planning as a Management Tool for School Principals in Rural Schools in the Motheo District. International Journal Education Science, 342348.

sheridan, D. H. (1998). An Analysis of Strategic Planning practices at Ontario Colleges of applied arts and Technology. Ottawa: National Library of Canada.

Stainer, G. A. (1997). The step by step Strategic Planning. New York: Free Press Paperbacks. 
WAHANA

e-ISSN 2654-4954,p-ISSN 0853-4403

Volume 72, Nomor 2, Desember 2020

Sugiyono. (2015). Metode Penelitian Pendidikan: Pendekatan Kuantitatif, Kualitatif $d a \quad R \& D$. Bandung: Alfabeta.

Sukmadinata, N. S. (2011). Metode Penelitian Pendidikan. Bandung: PT. Remaja Rosdakarya.

Tilaar, H. (2000). Paradigma baru pendidikan nasional. Jakarta: Rineka Cipta.

Wyk, C. V., \& Moeng, B. G. (2014). The Design and Implementation of A Strategic Plan In Primary Schools. International Business \& Economicws Research Journal, 137-143. 